\title{
Study of cyantraniliprole sorption in soils of Russia
}

Victoria Kolupaeva*, Inna Nyukhina, and Aleksandra Belik

All-Russia Research Institute of Phytopathology, 143050, Bolshie Vyazemy, Russia

\begin{abstract}
The sorption of the new insecticide cyantraniliprole was studied by the batch equilibrium method. The study of quantitative characteristics of cyantraniliprole sorption by the soils of different types showed that this process is well described by linear isotherms. According to obtained values of $\mathrm{K}_{\mathrm{oc}}$, cyantraniliprole belongs to medium-mobility active substances of pesticides. The sorption value of cyantraniliprole was closely correlated with the content of organic carbon and clay. The regression equation of the dependence of $K_{d}$ on soil organic carbon content was obtained.
\end{abstract}

\section{Introduction}

Cyantraniliprole is a new broad-spectrum insecticide. It is approved for use in Argentina, Canada, the USA, Great Britain and several EU countries. In the Russian Federation, cyantraniliprole was registered in 2019 as the active substance of insecticides recommended for pest control in plantings of cabbage, tomatoes, cucumbers and onions [1]. Laboratory filtration experiments showed high mobility of cyantraniliprole [2, 3]. In the lysimeter experiment cyantraniliprole was found in the leachate 2 weeks after its application (after heavy showers), and also was found in most samples during the experiment [4].

Pesticide sorption by soil is considered the process that has the greatest impact on pesticide behavior and fate in the environment $[5,6]$. Sorption is a result of the interaction of pesticides with soil colloids, non-colloidal organic matter of the soil and soil solution, and it can be reversible and irreversible. The extent of pesticide sorption to soil is expressed by the distribution coefficients between the aqueous and soil phases $\left(\mathrm{K}_{\mathrm{d}}\right)$. The distribution coefficient value varies widely with soil type and soil organic matter content, for this reason the sorption coefficient normalized to soil organic carbon content $\left(\mathrm{K}_{\mathrm{oc}}\right)$ is more often used [7].

Sorption indexes are necessary to assess the potential pesticide mobility in soil, and they are also widely used as input parameters to mathematical models of the pesticide behavior in soils. The accuracy of the prediction of pesticide migration in soil largely depends on the quality of input sorption data. Since in further studies it is planned to use the data of the sorption experiments for mathematical modeling of the behavior of cyantraniliprole in soils of Russia, the main goal of this work was to study the cyantraniliprole sorption in soils of the different climatic zones of the Russian Federation - Luvic Chernozem (Kursk region), Halpic Kastanozem (Saratov region) and Albic Glossic Retisol (Moscow, large lysimeter of Moscow State University) [9] and obtain quantitative characteristics of cyantraniliprole sorption.

* Corresponding author: v.kolupaeva@vniif.ru, amulanya@gmail.com 


\section{Objects and Methods}

\subsection{Pesticide}

Cyantraniliprole is a second-generation insecticide from class of anthranilamides, which is used on a wide range of crops and is effective against sucking pests and thrips. In terms of resistance it refers to low-persistent - persistent active substances: $\mathrm{DT}_{50}=8.7-91.9$ days $\left(\mathrm{DT}_{50 \text { geomean lab. }}=34.4\right.$ days $)$, in terms of migration ability it refers to medium-mobility active substances: $\mathrm{K}_{\mathrm{oc}}=157-367\left(\mathrm{~K}_{\mathrm{oc} \text { average }}=241 \mathrm{ml} / \mathrm{g}\right)[8]$.

\subsection{Soils}

The properties of soils are shown in Table 1.

Table 1. Physical and chemical properties of investigated soils.

\begin{tabular}{|c|c|c|c|c|c|c|c|}
\hline \multirow{2}{*}{ Soil } & \multirow{2}{*}{ Horizon } & \multirow{2}{*}{ Depths, cm } & \multirow{2}{*}{$\mathbf{C}_{\text {org., }} \%$} & \multirow{2}{*}{$\mathbf{p H}_{\mathbf{w}}$} & \multicolumn{3}{|c|}{ Particle size, \% } \\
\cline { 5 - 8 } & & & & & & & \\
\hline Luvic Chernozem & A & $0-24$ & 4.9 & 6.9 & 14.1 & 35.6 & 50.4 \\
\hline Halpic Kastanozem & A & $0-18$ & 2.5 & 7.1 & 51.1 & 21.1 & 27.8 \\
\hline \multirow{2}{*}{ Albic Glossic Retisol } & A & $0-36$ & 2.2 & 6.5 & 1.5 & 87.9 & 10.6 \\
\cline { 5 - 8 } & E-EB & $36-51$ & 0.7 & 6.1 & 1.0 & 91.5 & 7.5 \\
\hline
\end{tabular}

\subsection{Study of sorption kinetics for one concentration of cyantraniliprole in one soil}

The sorption study was carried out in accordance with the OECD methodology [10].

A preliminary experiment was conducted to study the sorption kinetics of cyantraniliprole in order to determine the time period for establishing equilibrium in the soil - solution system. At the first, $10 \mathrm{~g}$ of air-dried soil samples (Retisol, arable horizon) were sifted through a $1 \mathrm{~mm}$ sieve and placed in flasks, then $20 \mathrm{ml}$ of $0.01 \mathrm{M}$ solution of $\mathrm{CaCl}_{2}$ were added and flasks were shaken for 4 hours before the experiment. After that, $5 \mathrm{ml}$ of the test compound solution was added into the flasks to bring the final volume to $25 \mathrm{~cm}^{3}$ and to obtain cyantraniliprole concentration of $0.1 \mu \mathrm{g} / \mathrm{ml}$. Flasks were shaken for 16 hours.

Sampling was conducted after $0.1,2,4,8,12,16$ hours. The study was carried out in 2 replicates. The selected solutions were centrifuged at a speed of $4000 \mathrm{rpm}$ for $15 \mathrm{~min}$, equilibrium content of cyantraniliprole in the liquid phase was determined by high performance liquid chromatography (HPLC).

The solutions were prepared from an analytical standard containing $99.8 \%$ cyantraniliprole.

\subsection{Study of cyantraniliprole sorption}

At the first, $10 \mathrm{~g}$ of air-dried soil samples were sifted through a $1 \mathrm{~mm}$ sieve and placed in flasks, then $20 \mathrm{ml}$ of $0.01 \mathrm{M}$ solution of $\mathrm{CaCl}_{2}$ were added and flasks were shaken for 4 hours before the experiment. After that, $5 \mathrm{ml}$ of the test compound solution was added into the flasks to bring the final volume to $25 \mathrm{~cm}^{3}$ and to obtain cyantraniliprole concentration of 0.5 ; $0.2 ; 0.1 ; 0.05$ and $0.02 \mu \mathrm{g} / \mathrm{ml}$. The flasks were placed on a mechanical shaker; samples were taken for analysis after 16 hours. The study was carried out in 2 replicates. 


\subsection{Determination of cyantraniliprole in soil}

Quantitative determination of cyantraniliprole content in water and soil was carried out in accordance with the methodological guidelines [11]. Detection limits of cyantraniliprole were $0.5 \mu \mathrm{g} / \mathrm{L}$ and $2.5 \mu \mathrm{g} / \mathrm{kg}$ for water and soil respectively.

\subsection{Construction of isotherms and calculation of sorption coefficients}

The dependence of the sorption value of cyantraniliprole on its equilibrium concentration in solution was approximated by the equation of linear sorption isotherm:

$$
K_{d}=q / C_{e}
$$

where $K_{d}$ - sorption coefficients, $q$ - concentration of pesticide adsorbed on soil $(\mu \mathrm{g} / \mathrm{g})$, a $C_{e}$ - equilibrium concentration of pesticide in solution $(\mu \mathrm{g} / \mathrm{ml})$.

Since the soil organic matter plays a dominant role in the pesticide sorption, the sorption coefficient is often normalized by the content of soil organic carbon and $\mathrm{K}_{\mathrm{oc}}$ coefficient is used for a comparative assessment of the sorption ability of soils, regardless of the content of organic matter in them [7]. $\mathrm{K}_{\mathrm{oc}}$ value was calculated as:

$$
K_{o c}=\left(K_{d} \times 100\right) / C_{o r g}
$$

where $C_{\text {org }}-$ content of soil organic carbon (\%).

Moreover, the relationship between the concentration of adsorbed cyantraniliprole and its concentration in an aqueous solution was approximated by the Freundlich equation:

$$
q=K_{f} x C^{1 / n}
$$

where $K_{f}$ and $1 / n$ are the Freundlich coefficient and the Freundlich exponent, which indicate the affinity of the soil for the pesticide and the degree of linearity between the amounts adsorbed and the solution concentration, respectively.

\section{Results and discussion}

The preliminary experiment on determining the time to reach equilibrium in the soil-solution system for cyantraniliprole showed (Fig. 1) that after 8 hours of the experiment, the sorption rate decreases significantly, and 16 hours are enough to achieve the equilibrium of cyantraniliprole between solid and liquid phases.

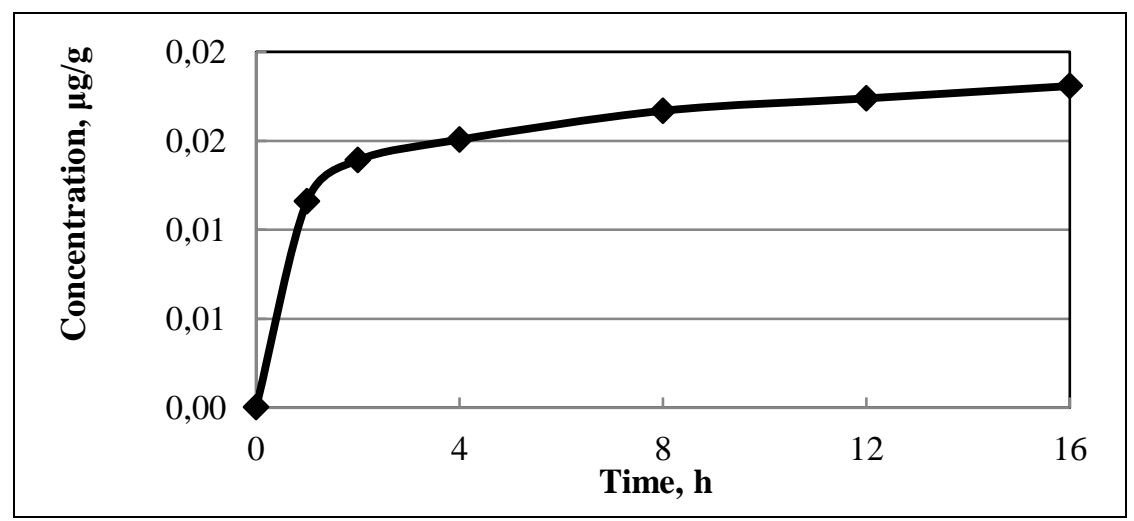

Fig. 1. Sorption kinetics of cyantraniliprole in soil. 
The sorption of cyantraniliprole is well described by linear isotherms (Fig. 2), which allows to use a simple and universal index, the distribution coefficient $\left(\mathrm{K}_{\mathrm{d}}\right)$. The values of $\mathrm{K}_{\mathrm{d}}$, as well as Freundlich coefficient $\left(\mathrm{K}_{\mathrm{f}}\right)$ and Freundlich exponent $(1 / \mathrm{n})$ are shown in Table 2. The values of determination coefficient $R^{2}$ indicate that the accuracy of the description of the obtained data is higher when using the linear equation. For linear equation all values of $\mathrm{R}^{2}$ are above 0.99 .

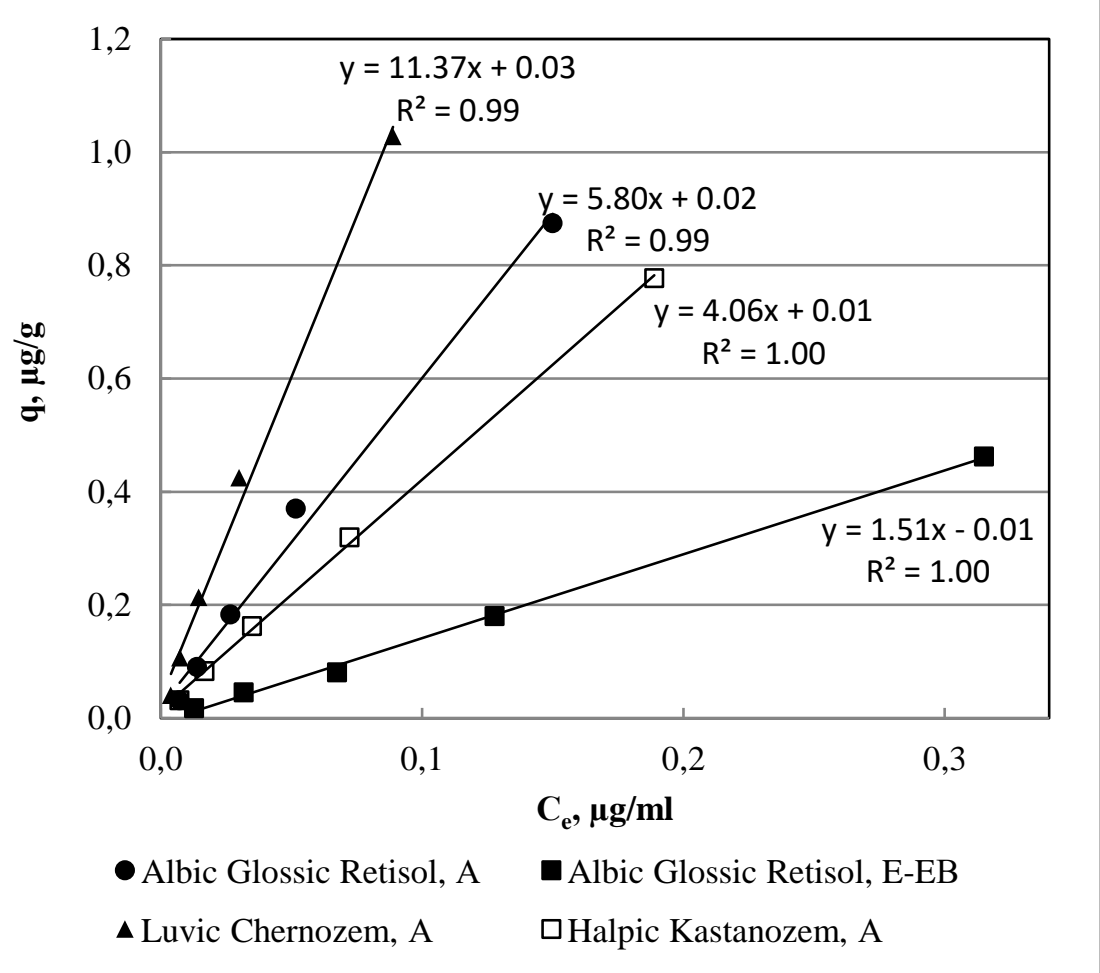

Fig. 2. Isotherms of cyantraniliprole sorption.

Table 2. Sorption parameters of cyantraniliprole for Freundlich equation and linear sorption model.

\begin{tabular}{|c|c|c|c|c|c|c|}
\hline Soil, horizon & $\mathbf{K}_{\mathbf{d}}{ }^{*}$ & $\mathbf{R}^{\mathbf{2}}$ & $\mathbf{K}_{\mathbf{0 c}}{ }^{* *}$ & $\mathbf{K}_{\mathbf{f}}^{* * *}$ & $\mathbf{1}^{* \mathbf{n}^{* * * * *}}$ & $\mathbf{R}^{\mathbf{2}}$ \\
\hline Halpic Kastanozem, A & $4.06 \pm 0.22$ & 0.999 & 185 & $4.07 \pm 1.35$ & $0.97 \pm 0.09$ & 0.998 \\
\hline Luvic Chernozem, A & $11.37 \pm 1.78$ & 0.993 & 258 & $13.80 \pm 2.88$ & $1.01 \pm 0.24$ & 0.984 \\
\hline Albic Glossic Retisol, A & $5.80 \pm 0.31$ & 0.992 & 387 & $7.94 \pm 1.45$ & $1.07 \pm 0.08$ & 0.991 \\
\hline Albic Glossic Retisol, E-EB & $1.49 \pm 0.11$ & 0.998 & 229 & $3.02 \pm 9.33$ & $1.41 \pm 0.59$ & 0.916 \\
\hline
\end{tabular}

* Linear adsorption coefficient with 95\% confidence interval;

** linear adsorption coefficient normalized for organic carbon with $95 \%$ confidence interval;

$* * *$ Freundlich adsorption coefficient with $95 \%$ confidence interval;

$* * * *$ Freundlich exponent with $95 \%$ confidence interval

The values of the sorption coefficient varied from 1.49 in the mixed horizon E-EB of Albic Glossic Retisol to 11.37 in the arable layer of Luvic Chernozem. Sorption coefficients normalized to soil organic carbon content $\left(\mathrm{K}_{\mathrm{oc}}\right)$ ranged from 185 (in the arable horizon of Halpic Kastanozem) to $387 \mathrm{ml} / \mathrm{g}$ (in the arable layer of Albic Glossic Retisol), which allowed cyantraniliprole to be classified as a medium-mobile pesticides [12]. These data generally 
correspond to the results of cyantraniliprole registration research conducted in $\mathrm{EU}\left(\mathrm{K}_{\mathrm{d}}=2.51\right.$

- 7.14, $\left.\mathrm{K}_{\mathrm{oc}}=157-367 \mathrm{ml} / \mathrm{g}\right)$ [13], $\left(\mathrm{K}_{\mathrm{oc}}=251 \mathrm{ml} / \mathrm{g}\right)$ [2].

All obtained $\mathrm{K}_{\mathrm{d}}$ values are significant at a $0.01 \%$ significance level.

The highest value of $\mathrm{K}_{\mathrm{oc}}$ was obtained for the arable horizon of Albic Glossic Retisol, this suggests that, in addition to organic matter, mineral part of soil is also involved in the sorption of the pesticide.

To determine the factors affecting the cyantraniliprole sorption, the regression equations were obtained (determination coefficients $\mathrm{R}^{2}$ are given in Table 3 ).

Table 3. Determination coefficients of regression relationship of sorption coefficient $\mathrm{K}_{\mathrm{d}}$ to soil properties.

\begin{tabular}{|c|c|c|c|c|}
\hline Corg., \% & Clay, \% & pH & Silt, \% & $\mathbf{R}^{2}$ \\
\hline $\mathrm{x}$ & & & & 0.94 \\
\hline & $\mathrm{x}$ & & & 0.73 \\
\hline & & $\mathrm{x}$ & & 0.01 \\
\hline & & & $\mathrm{x}$ & 0.20 \\
\hline $\mathrm{x}$ & $\mathrm{x}$ & & & 0.97 \\
\hline
\end{tabular}

According to the Table 3, the sorption coefficient most depends on the content of organic matter $\left(R^{2}=0.94\right)$ and clay $\left(R^{2}=0.73\right)$ in the soil. The regression equation of the dependence of the sorption coefficient on the soil organic carbon content has the following form $\left(\mathrm{R}^{2}=\right.$ $0,94)$ :

$$
K d=2,23 \times \operatorname{Corg}-0,33
$$

\section{Conclusions}

1. The study of quantitative characteristics of cyantraniliprole sorption by the different soils showed that this process is well described by linear isotherms $\left(\mathrm{R}^{2}=0.99\right.$ for all soils $)$.

2. According to obtained values of $\mathrm{K}_{\mathrm{oc}}$, cyantraniliprole belongs to medium-mobile pesticides.

3. The sorption coefficient of cyantraniliprole was closely correlated with the content of organic carbon and clay.

\section{References}

1. Gosudarstvennyj katalog pesticidov i agrohimikatov URL:

http://mcx.ru/ministry/departments/departament-rastenievodstva-mekhanizatsii-khimizatsiii-zashchity-rasteniy/industry-information/info-gosudarstvennaya-usluga-pogosudarstvennoy-registratsii-pestitsidov-i-agrokhimikatov/ (in Russian)

2. N. Vela, G. Pérez-Lucas, M.J. Navarro, I. Garrido, J. Fenoll, S. Navarro, Bull. Environ. Contam. Toxicol., 99(4), 465 (2017)

3. E. Shein, A. Belik, A. Kokoreva, V. Kolupaeva, P. Pletenev, Moscow Univ. Soil Sci. Bull., 72(4), 185 (2017)

4. V. Kolupaeva, A. Kokoreva, A. Belik, P. Pletenev, Open Agriculture, 4, 599 (2019)

5. R. Green, S. Karickhoff, Pesticides in the Soil Environment: Processes, Impacts, and Modeling. Soil Science Society of America Book Series 2. Soil Science Society of America, Madison, WI, 79 (1990)

6. Z. Gerstl, Crop Prot, 19, 643 (2000) 
7. D. I. Gustafson, Environ. Toxico.l Chem. 8, 339 (1989)

8. PPDB - Pesticide Properties Database URL: https://sitem.herts.ac.uk/aeru/ppdb/en/

9. IUSS Working Group WRB. 2015. World Reference Base for Soil Resources 2014, update 2015 International soil classification system for naming soils and creating legends for soil maps. World Soil Resources Reports No. 106. (FAO, Rome, 2015)

10. Adsorption - Desorption Using a Batch Equilibrium Method. OECD guideline for the testing of chemicals. Test No. 106. (US EPA, 2000)

11. Opredelenie ostatochnyh kolichestv ciantraniliprola v vode, pochve, kapuste, plodah tomata i tomatnom soke, v luke pere i luke repke metodom vysokoeffektivnoj zhidkostnoj hromatografii Metodicheskie ukazaniya, 32 (Federal'nyj centr gigieny i epidemiologii Rospotrebnadzora, Moscow, 2015) (In Russian)

12. Metody ocenki ekologicheskoj opasnosti pesticidov pri ih registracii (Rukovodstvo po klassifikaciyam ekologicheskoj opasnosti pesticidov) (VNIIF, 2010) URL: http://penreg.ru/pesticide-ecological-evaluation/opasnost.html (in Russian)

13. Conclusion on the peer review of the pesticide risk assessment of the active substance cyantraniliprole, EFSA Journal, 12, 9 (2014) 